\title{
A phase I I trial of neoadjuvant doxorrubicin plus gemcitabine, followed by weekly paclitaxel in lo- cally advanced breast cancer: an analysis of effectiveness and toxicity
}

\author{
Cristiane R Petrarca ${ }^{1}$, Sheila Calleari ${ }^{2}$, Alessandra Morelle ${ }^{3}$, Marcio Debiasi ${ }^{4}$, Giselle Pereira de \\ Carvalho ${ }^{5}$, Bernardo Garicochea ${ }^{6}$
}

1. Hospital Universitário da Universidade Federal de Pelotas, Rua Professor Araújo, Pelotas, RS, Brazil. 2. Hospital São Lucas da PUCRS, Avenida I piranga, Porto Alegre, RS, Brazi. 3. Hospital Moinhos de Vento Rua Tiradentes, Porto Alegre, RS, Brazil. 4. Hospital São Lucas da PUCRS, Avenida I piranga, Porto Alegre, RS, Brazil. 5. Hospital São Lucas da PUCRS, Avenida I piranga, Porto Alegre, RS, Brazil. 6. Hospital São Lucas da PUCRS, Avenida Ipiranga, Porto Alegre, RS, Brazil

Correspondence: Cristiane Rios Petrarca. Address: Hospital Universitário da Universidade Federal de Pelotas Rua Professor Araújo, Pelotas, RS, Brazil. Telephone: 555-332-224-957. Fax: 555-332-224-957. E-mail:crispetrarca@bol.com.br

Received: March 16, 2012

DOI : $10.5430 /$ jst.v2n4p19
Accepted: July 5, 2012

Published: August 1, 2012

URL: http://dx.doi.org/10.5430/jst.v2n4p19

\section{Abstract}

Background: Neoadjuvant chemotherapy is a therapeutic strategy for patients with locally advanced breast cancer. To evaluate the toxicity and clinical efficacy of the combination of Gemcitabine plus doxorubicin followed by paclitaxel in neoadjuvancy.

Methods: A phase II trial, in which 19 patients, ages 37 to 65, with pathologically proven breast cancer, were included. They received four cycles of doxorubicin $50 \mathrm{mg} / \mathrm{m}^{2}$ on day 1 and Gemcitabine $1000 \mathrm{mg} / \mathrm{m}^{2}$ on days 1 and 8 , every 21 days; followed by four cycles of paclitaxel $80 \mathrm{mg} / \mathrm{m}^{2}$ on days 1,8 , and 15, every 28 days. The follow-up was performed with mammography and clinical examination.

Results: The planned regimen was completed in 17 (89.4\%) of the 19 patients. Thirty seven percent of the patients presented mucositis grades 3-4 and 15\% had diarrhea grades 3-4. Hematologic toxicities grades 3-4 were seen in $31.5 \%$ of the cases (6 patients). Complete clinical response was observed in 9 (47\%) patients; of whom four showed complete pathological response after surgery.

Conclusion: The response rate (clinical and pathological) in this study was similar to the one observed in the usual regimen of neoadjuvancy using doxorubicin, cyclophosphamide, and paclitaxel. However, the toxicity profile of the combination regimen containing gemcitabine was exceedingly high, causing the interruption of the protocol.

\section{Key words}

Breast neoplasms, Neoadjuvant chemotherapy, Gemcitabine, Doxorubicin, Paclitaxel 


\section{Introduction}

The number of Brazilian women with the diagnosis of locally advanced or metastatic breast cancer is considerably high. It is estimated that $28 \%$ of the new diagnosed cases in the country are stage III disease ${ }^{[1]}$. Locally advanced breast cancer is generally treated with a combination of cytotoxic drugs before the surgical procedure (neoadjuvancy). The neoadjuvancy not only increases the chances of a later conservative surgery of the breast, but also permits the evaluation of the objective response and chemosensitivity to the drugs that are being used. Moreover, it is possible that this therapeutic modality acts in a way to attack early micrometastatic disease. Complete pathological response is observed in one out of every five or six patients and is directly correlated to survival advantage, which makes it a very important endpoint in the evaluation of new neoadjuvant treatment strategies in breast cancer ${ }^{[2,3,4]}$.

The most appropriate drug combination for neoadjuvancy is still under debate. Over the years, the combination of an alkylant and anthracyclin followed by a taxane has become the most popular choice of neoadjuvancy worldwide. The main study to support this option of therapy stems from the NSABP B-27 trial, which compared the use of doxorubicin and cyclophosphamide (AC) followed by docetaxel (T) before and after the surgery. The patients who received triplet therapy before surgery fared better ${ }^{[5]}$. More recently, the results of neoadjuvancy seemed to improve with the use of weekly paclitaxel after AC, with significant gains in disease-free-survival and overall survival ${ }^{[6]}$.

Gemcitabine is a pyrimidine analogue with well-known activity in advanced breast cancer, providing responses in 25-46\% of the patients, with a mild toxicity profile ${ }^{[7,8,9]}$. Previous studies combining gemcitabine to anthracyclins (AG) in advanced breast cancer have indicated clinical benefit in $25-55 \%$ of the cases ${ }^{[10,11,12]}$. Based on these reports, the AG combination was moved to the neoadjuvant setting, showing a promising response rate. On the other hand, the toxicity profile is a matter of debate, since mucositis and neutropenia are common and intense. For this reason, some authors advocate for the use of granulocyte stimulating factor, while others do not ${ }^{[13,14,15]}$. The response rates were similar to the ones previously described in the combination of anthracyclin and taxanes ${ }^{[16,17]}$.

The aim of the present study was to evaluate the toxicity profile of a neoadjuvant combination of gemcitabine plus anthracyclin, followed by weekly paclitaxel (AG-T) in advanced breast cancer patients treated in the Brazilian Public Health System ("Sistema Único de Saúde” - SUS). Clinical responses were also observed to decide if there are grounds for a further phase III study.

\section{Materials/ patients and methods}

This phase II clinical trial was designed to evaluate the toxicity profile of AG-T neoadjuvant in a series of patients with locally advanced breast cancer (stages IIB or III). The inclusion criteria were: women ages 18 and up, Karnofsky's performance status score over $80 \%$, neutrophils $>1,000 / \mathrm{mm}^{3}$, platelets over $100,000 / \mathrm{mm}^{3}$, hemoglobin $>10.0 \mathrm{~g} / \mathrm{dl}$, normal hepatic and renal function, and no previous history of malignant tumors.

Patients received four cycles of AG every 21 days (doxorubicin $50 \mathrm{mg} / \mathrm{m}^{2}$ on day 1 and Gemcitabine $1000 \mathrm{mg} / \mathrm{m}^{2}$ on days 1 and 8) followed by four $\mathrm{T}$ cycles every 28 days (paclitaxel $80 \mathrm{mg} / \mathrm{m}^{2}$ on days 1,8 , and 15). The surgical procedure (mastectomy or lumpectomy) was carried out 4 to 6 weeks after the end of the last paclitaxel cycle. The choice of surgical procedure and treatment after surgery were at the attending physician's discretion.

Mammography and breast ultrasound were originally planned to be performed before the beginning of the chemotherapy, after the first four cycles of AG and after the end of the last paclitaxel cycle. However, the protocol could not be followed, because the study was conducted in patients treated in the Brazilian Public Health System (SUS) and those exams were not 
available to be executed as planned. All patients were submitted to at least one mammography before the beginning of the chemotherapy. Breast Magnetic Resonance Imaging was not performed because the Brazilian Public Health System does not offer it to patients. All women were followed with physical examination performed at every medical consultation, when the tumor size was clinically accessed and toxicity was evaluated by Common Toxicity Criteria (CTC version 3.0).

Complete clinical response was defined as no evidence of tumor on the physical exam, whereas partial clinical response was defined as a reduction in tumor size greater than $50 \%$. Reduction of less than $50 \%$ or an increase up to $20 \%$ was considered stable disease and an increase of more than $20 \%$ in tumor size was considered progression disease.

The protocol was approved by the institutional committee of ethics in research and by the Brazilian national committee of ethics in research. All patients were required to give written consent to enter the study.

\section{Results}

Table 1. Baseline patients and tumors characteristics

\begin{tabular}{ll}
\hline Patients and tumors characteristics & $\mathbf{N}(\%) /$ median (range) \\
\hline Age (years) & $52.5(35-57)$ \\
Pre-chemotherapy TNM stage & $5(26.4 \%)$ \\
T3N0M0 & $1(5.2 \%)$ \\
T4N0M0 & $6(31.6 \%)$ \\
T3-4N1M0 & $6(31.6 \%)$ \\
T2-4N2M0 & $1(5.2 \%)$ \\
T2-4N3M0 & \\
Hormone receptor status & $10(52.6 \%)$ \\
Positive & $9(47.4 \%)$ \\
Negative & \\
Cerb-B2 & $5(26.4 \%)$ \\
Cerb-B2 +++ & $2(10.4 \%)$ \\
Cerb-B2 ++ & $12(63.2 \%)$ \\
Cerb-B2 + or 0 & $19(100 \%)$ \\
Total &
\end{tabular}

From November 2005 to February 2007, 19 patients with invasive ductal carcinoma stages IIB and III were selected for the study. The patient's baseline clinical characteristics are displayed in Table 1. It is very important to state that the four patients classified as having T2 had a clinically positive axilla before initiating the study protocol. The neoadjuvant treatment was not thoroughly applied in two patients. Patient number five presented grade 3 long-lasting hepatotoxicity after the fourth cycle of AG. Patient number six achieved maximum tumor response at the first paclitaxel cycle, but presented an increase in her tumor dimensions during the third paclitaxel cycle, at which time she was immediately sent to surgery. The reduction of the tumors' largest diameters can be verified for each patient in Figure 1.There was no significant difference in clinical response between patients with positive and negative hormonal receptors.

Nine patients (47.3\%) had a complete clinical response after AG-T, and four (21\%) of those patients with complete clinical response also presented complete pathological response. The other ten patients had partial responses (47.3\%). Nevertheless, as it was previously described, one of those patients with partial response had her treatment stopped because of liver toxicity and another one was sent to surgery before the end of the chemotherapy because her tumor increased in diameter during the taxane cycles. This patient did not meet criteria to progressive disease (increase higher than $20 \%$ in tumor diameter); however, this decision was on her attending physician discretion. Table 2 shows the clinical and Published by Sciedu Press 
pathological stagings before and after chemotherapy, the tumor's largest diameters before and after chemotherapy, and the surgical procedure that each patient was submitted to. It is important to state that all patients were submitted to axillary lymph node dissection and not to sentinel lymph node dissection due to technical conditions at the institution where the study was carried out.

Table 2. Description of TNM clinical staging, clinical largest tumor diameter before chemotherapy, largest tumors' diameter after chemotherapy, surgical procedure and axillary pathological status

\begin{tabular}{|c|c|c|c|c|c|}
\hline $\begin{array}{l}\text { Patient } \\
\text { identi- } \\
\text { fication } \\
\text { number }\end{array}$ & $\begin{array}{l}\text { TNM } \\
\text { clinical } \\
\text { staging }\end{array}$ & $\begin{array}{l}\text { TNM } \\
\text { pathological } \\
\text { staging }\end{array}$ & $\begin{array}{l}\text { Clinical largest } \\
\text { palpable tumor } \\
\text { diameter before } \\
\text { chemotherapy } \\
\text { (cm) }\end{array}$ & $\begin{array}{l}\text { Clinical largest palpable } \\
\text { tumor diameter after } \\
\text { chemotherapy }(\mathrm{cm})\end{array}$ & Surgery \\
\hline 1 & T2N+ & $\mathrm{NA}^{* * * *}$ & 3.0 & NP* & Patient declined procedure \\
\hline 2 & T3N0 & $\mathrm{CPR}^{* * * * *}$ & 5.0 & NP* & BCS + ALND ** \\
\hline 3 & T3N+ & $\mathrm{NA}^{* * * *}$ & 5.0 & 1.4 & Patient declined procedure \\
\hline 4 & $\mathrm{~T} 4 \mathrm{~N}^{+}$ & $\mathrm{NA}^{* * * *}$ & 4.6 & 2.0 & MRM + ALND $* * *$ \\
\hline 5 & T3N+ & $\mathrm{T} 2 \mathrm{~N}+$ & 6.5 & 4.0 & MRM + ALND *** \\
\hline 6 & T3N+ & $\mathrm{CPR}^{* * * * *}$ & 8.0 & NP* & MRM + ALND *** \\
\hline 7 & T4N0 & $\mathrm{T} 2 \mathrm{~N}+$ & 11.3 & 4.5 & MRM + ALND *** \\
\hline 8 & $\mathrm{~T} 2 \mathrm{~N}+$ & $\mathrm{CPR}^{* * * * *}$ & 4.8 & NP* & MRM + ALND *** \\
\hline 9 & $\mathrm{~T} 4 \mathrm{~N}^{+}$ & TxN+ & 7.0 & NP* & MRM + ALND *** \\
\hline 10 & T3NO & $\mathrm{NA}^{* * * *}$ & 9.4 & 1.5 & BCS + ALND ** \\
\hline 11 & $\mathrm{~T} 4 \mathrm{~N}+$ & $\mathrm{T} 2 \mathrm{~N}+$ & 15.0 & 5.0 & MRM + ALND $* * *$ \\
\hline 12 & T4N+ & $\mathrm{T} 2 \mathrm{~N}+$ & 4.0 & 3.5 & MRM + ALND *** \\
\hline 13 & $\mathrm{~T} 4 \mathrm{~N}^{+}$ & $\mathrm{T} 2 \mathrm{~N}+$ & 9.5 & 2.5 & MRM + ALND *** \\
\hline 14 & T3NO & $\mathrm{CPR}^{* * * * * *}$ & 6.5 & NP* & BCS + ALND ** \\
\hline 15 & T3N+ & $\mathrm{TxN}^{+}$ & 9.5 & NP* & MRM + ALND $* * *$ \\
\hline 16 & T3N+ & $\mathrm{T} 1 \mathrm{~N}^{+}$ & 10.5 & 1.5 & BCS + ALND ** \\
\hline 17 & T3N+ & TxN+ & 7.0 & NP* & BCS + ALND ** \\
\hline 18 & $\mathrm{~T} 2 \mathrm{~N}+$ & TxN+ & 3.0 & NP* & BCS + ALND ** \\
\hline 19 & T3NO & $\mathrm{TxN}^{+}$ & 5.0 & NP* & MRM + ALND *** \\
\hline
\end{tabular}

* NP: non-palpable tumor

** BCS + ALND: breast conserving surgery plus axillary lymph node dissection

*** MRM + ALND: modified radical mastectomy plus axillary lymph node dissection

**** NA: not-available

***** CPR: complete pathological response

The adverse effects related to the treatment are shown in the Table 3. As mentioned, Grade 3 liver toxicity was observed in one patient. Six patients (31.5\%) presented hematologic toxicity grades 3 and 4, with severe neutropenia in five of them. Mucositis was reported in all patients, seven (36.8\%) of which had grades 3 and 4 . Thirteen patients complained of periods of nausea, but it was considered as intense (Grades 3 and 4) in only three of them. Grades 3 and 4 diarrhea, were reported in 3 patients (15.7\%). 


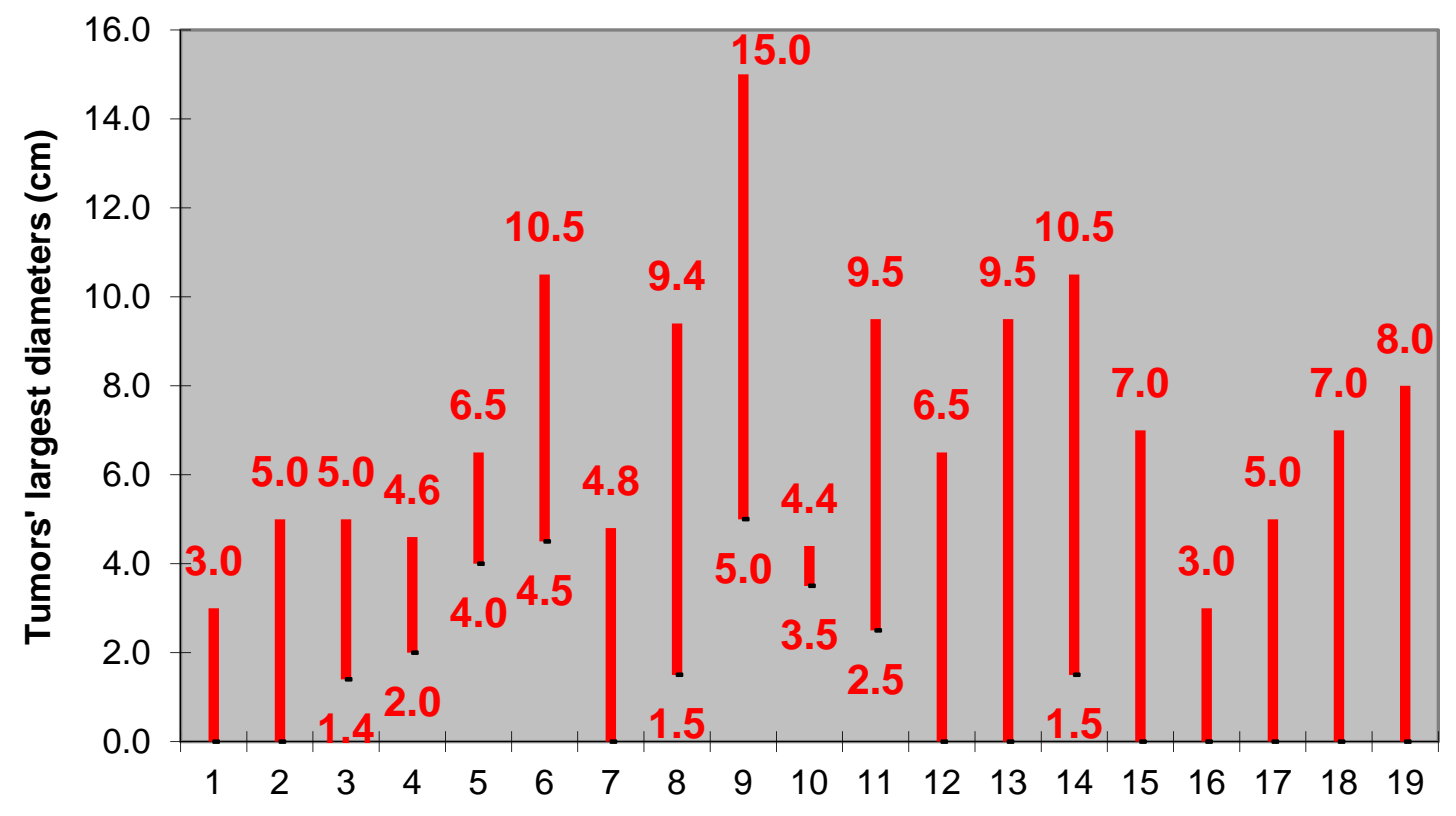

Patient identification number

Figure 1. Tumors' largest diameters before (at the top of the lines) and after (at the bottom of the lines) neoadjuvant chemotherapy for each patient incuded in the study. * Data regarding patient number six refers to her best response.

Table 3. Adverse events with doxorubicin plus gemcitabine followed by weekly paclitaxel

\begin{tabular}{lllll}
\hline Effect & Grade 1 (n) & Grade 2 (n) & Grade 3 (n) & Grade 4 (n) \\
\hline Alopecia & 2 & 11 & - & - \\
Anemia & 8 & 9 & 2 & - \\
Anorexia & 1 & 1 & - & - \\
Diarrhea & 2 & 2 & 3 & - \\
Fatigue & 3 & 3 & - & - \\
Febrile neutropenia & - & 2 & - & 2 \\
Mucositis & 3 & 9 & 7 & - \\
Myalgia/arthralgia & 1 & 2 & - & - \\
Nausea/vomiting & 7 & 8 & - & - \\
Neutropenia & 5 & 3 & 1 & 1 \\
Thrombocytopenia & 3 & - & - & - \\
Total & 35 & 50 & 13 & 3 \\
\hline
\end{tabular}

\section{Discussion}

Despite the small number of recruited patients for the study, we could observe that the combination of gemcitabine with doxorubicin followed by weekly paclitaxel is capable of producing clinical and pathological responses in neoadjuvancy in locally advanced breast cancer. In this group of patients with extensive tumors, the complete pathological response rate was slightly over $20 \%$, a figure close to the one reported in more classical combinations such as AC-T (cyclophosphamide with doxorubicin followed by docetaxel). Other phase II studies that evaluated the efficacy of gemcitabine in neoadjuvant treatment have presented similar rates of pathological response. For instance, three recent trials obtained $18-23 \%$ of complete pathological response. One of these combined gemcitabine, epirubicin, and docetaxel, while the others used gemcitabine with epirubicin and paclitaxel or dose-dense gemcitabine, epirubicin and albumin-bound paclitaxel ${ }^{[14,18,19]}$. 
Data from studies conducted in women with advanced disease in which the same three-drug combination was used in different dosing schedules also suggests that this regimen is highly active, but at expense of high hematological toxicity. The overall response rates, including partial and complete responses, ranged from 55.2 to $82.9 \%$, while grades III-IV neutropenia ranged from 41 to $69 \%$. In a phase II trial conducted by Passardi and colleagues, $27 \%$ of patients required the use of granulocyte colony-stimulating factor ${ }^{[20-23]}$.

In our data, the most concerning toxic effects of the combination studied were neutropenia and mucositis, requiring the hospitalization of seven over 19 patients (36.8\%). This type of complication had been reported with gemcitabine combinations for neoadjuvant treatment in significantly variable rates (10 to 54\%), making some authors to advocate for the use of granulocyte stimulating factor during the AG phase, while others do not ${ }^{[9,13-15,18,19]}$.In our study, the use of weekly paclitaxel seemed not to have potentiated the neutropenic effect, which was more related to the AG combination, as observed in other studies ${ }^{[14,24,25]}$. Mucositis was much more frequent in our study than reported in other gemcitabine-combination strategies. Grade 3 and 4 mucositis have been reported in 0.5 to $3 \%$ of cases in these studies. We have observed this complication in $36.8 \%$ of our patients. Grade 3 and 4 diarrheas were also more frequent in our group of patients: $15.7 \%$ versus $3-5 \%$ in previous studies. It is conceivable that the higher rate of severe hematologic and non-hematologic complications could be related to the type of anthracycline used: epirubicin versus doxorubicin. Further evidence showing that the use of sequential gemcitabine and doxorubicin has a highly toxic hematological profile came from an Indian study published soon after we had terminated the accrual of our study. The use of different schedules of gemcitabine and doxorubicin in this study demonstrated that a subgroup of patients that had received gemcitabine on days 1 and 8 and doxorubicin on day 2 presented an unacceptable rate of severe neutropenia and mucosites (80\% of the cases) ${ }^{[14]}$. It is possible that the use of prophylactic granulocyte colony-stimulating factor may reduce the toxicities of AG-T, and this strategy may be worthy of evaluation in further phase III studies, since the efficacy of the combination seems to be equivalent to the therapies presently recommended for neoadjuvancy.

Despite the fact that previous studies showed evidence that positive hormonal receptors is a predictor of bad response to neoadjuvant chemotherapy, our data does not corroborate this finding, since there was no difference between those groups, probable due to the lack of power of our study. Many recent studies, conducted in very different settings of neoadjuvant chemotherapy protocols, show that the tumors' genotype and phenotype profile are important response predictors ${ }^{[26-30]}$.

\section{Conclusion}

Despite the limitations of the study, the efficacy data from this trial, regarding clinical and pathological responses rates, was similar to the one observed in the usual regimen of neoadjuvancy using doxorubicin, cyclophosphamide, and paclitaxel. However, the toxicity profile of the experimental regimen used in our study was exceedingly high, causing the interruption of the protocol.

\section{Competing interests}

The authors don't have any competing interests to declare.

\section{Funding}

The paper was not funded by any institution. Patients were treated with the Brazilian Public Health System resources.

\section{References}

[1] Fundação Oncocentro de São Paulo. Registro hospitalar de cancer no Estado de São Paulo. Cad FOSP. Nov 2003.

[2] Bonadonna G, Valagussa P, Brambilla C, Ferrari L, Moliterni A, Terenziani M, et al. Primary chemotherapy in operable breast cancer: eight-year experience at the Milan Cancer Institute. J Clin Oncol. 1998; 16(1): 93-100. PMid:9440728 
[3] Fisher B, Bryant J, Wolmark N, Mamounas E, Brown A, Fisher ER, et al. Effect of preoperative chemotherapy on the outcome of women with operable breast cancer. J Clin Oncol. 1998; 16(8): 2672-85. PMid:9704717

[4] Kuerer HM, Newman LA, Smith TL, Ames FC, Hunt KK, Dhingra K, et al. Clinical Course of breast cancer patients with complete pathologic primary tumor and axillary lymph node response to doxorubicin-based neoadjuvant chemotherapy. J Clin Oncol. 1999; 17: 441-4. PMid:10080583

[5] Bear HD, Anderson S, Brown A, Smith R, Mamounas P, Fisher B, et al. The effect on tumor response of adding preoperative docetaxel to preoperative doxorrubicin and cyclophosphamide: preliminary results from National Surgical Adjuvant Breast and Bowel Project protocol B-27. J Clin Oncol. 2003; 21(22): 4165-74. PMid:14559892 http://dx.doi.org/10.1200/JCO.2003.12.005

[6] Sparano JÁ, Wang M, Martino S, Jones V, Perez EA, Saphner T, et al. Weekly Paclitaxel in the Adjuvant Treatment of Breast Câncer. N Engl J Med. 2008; 358(16): 1663-71. PMid:18420499 http://dx.doi.org/10.1056/NEJMoa0707056

[7] Possinger K, Kaufman M, Coleman R, Stuart NSA, Helsing M, Ohnmacht U, et al. Phase II study of gemcitabine as first line chemotherapy in patients with advanced or metastatic breast cancer. Anticancer Drugs. 1997; 10(2): 155-62. PMid:10211545 http://dx.doi.org/10.1097/00001813-199902000-00003

[8] Carmichael J, Possinger K, Philip P, et al. Advanced breast cancer: a phase II trial with gemcitabine. J Clin Oncol. 1995; 13: 2731-6. PMid:7595731

[9] Spielmann M, Llombart-Cussac A, Kalla S, Espié M, Namer M, Ferrero JM, et al. Single-agent gemcitabine is active in previously treated metastatic breast cancer. Oncology. 2001; 60(4): 303-7. PMid:11408796 http://dx.doi.org/10.1159/000058524

[10] Luftner D, Flath B, Akrivakis C, Mergenthaler HG, Ohnmacht U, Arning M, et al. Gemcitabine plus dose-escalated epirubicin in advanced breast cancer: results of a phase I study. Invest New Drugs. 1998; 16(2): 141-6. http://dx.doi.org/10.1023/A:1006121608414

[11] Delacroix J, Dieras V, Viens P, Fumoleau P, Espie M, Pujade-Lauraine E, et al. Gemzar and epirubicin (EP) in patients with metastatic breast cancer (MBC): preliminary results of a phase I study. Proc Am Soc Clin Oncol. 1998; 17: 136 (Abstract \# 520).

[12] Perez-Manga G, Lluch A, Alba E, Moreno-Nogueira JA, Palomero M, García-Conde J, et al. Gemcitabine in combination with doxorubicin in advanced breast cancer: final results of a phase II pharmacokinetic trial. J Clin Oncol. 2000; 18(13): $2545-52$. PMid:10893285

[13] Artioli G, Mocellin S, Borgato L, Cappetta A, Bozza F, Zavagno G, et al. Phase II study of neoadjuvant gemcitabine, pegylated liposomal doxorubicin, and docetaxel in locally advanced breast cancer. Anticancer Res. 2010; 30 (9): 3817-21. PMid:20944176

[14] Yardley DA, Zubkus J, Daniel B, Inhorn R, Lane CM, Vazquez ER, et al. A phase II trial of dose-dense neoadjuvant gemcitabine, epirubicin, and albumin-bound paclitaxel with pegfilgrastim in the treatment of patients with locally advanced breast cancer. Clin Breast Cancer. 2010; 10 (5): 367-72. PMid:20670921 http://dx.doi.org/10.3816/CBC.2010.n.048

[15] Sánchez-Muñoz A, Dueñas-García R, Jaén-Morago A, Carrasco E, Chacón I, García-Tapiador AM, et al. Is it possible to increase pCR in the neoadjuvant treatment with a dose-dense/sequential combination?: results from a phase II Trial combining epirubicin and cyclophosphamide followed by paclitaxel and gemcitabine \pm trastuzumab in stage II and III breast cancer patients. Am J Clin Oncol. 2010; 33 (5): 432-7. PMid:19952716

[16] Gómez H, Kahatt C, Falcon S, Santillana S, de Mendoza FH, Valdivia S, et al. A phase II study of neoadjuvant gemcitabine plus doxorubicin in stage IIIB breast cancer: a preliminary report. Semin Oncol. 2001; 28(3 suppl 10): 57-61. PMid:11510035 http://dx.doi.org/10.1053/sonc.2001.22532

[17] Julka PK, Chacko RT, Nag S, Parshad R, Nair A, Oh DS, et al. A phase II study of sequential neoadjuvant gemcitabine plus doxorubicin followed by gemcitabine plus cisplatin in patients with operable breast cancer: prediction of response using molecular profiling. Br J Cancer. 2008; 98(8): 1327-35. PMid:18382427 http://dx.doi.org/10.1038/sj.bjc.6604322

[18] Yardley DA, Peacock NW, Dickson NR, White MB, Vázquez ER, Foust JT, et al. A Phase II Trial of Neoadjuvant Gemcitabine, Epirubicin, and Docetaxel as Primary Treatment of Pacients with Locally Advanced or Inflammatory Breast Cancer. Clil Breast Cancer. 2010; 10 (3): 217-23. PMid:20497920 http://dx.doi.org/10.3816/CBC.2010.n.029

[19] Hamm JT, Wilson JW, Rastogi P, Lembersky BC, Treng GC, Song YK, et al. Gemcitabine/Epirubicin/Paclitaxel as Neoadjuvant Chemotherapy in Locally Advanced Breast Cancer: A Phase II Trial of the NSABP Foundation Research Group. Clin Breast Cancer. 2008; 8(3): 257-63. PMid:18650156 http://dx.doi.org/10.3816/CBC.2008.n.029

[20] Passardi A, Massa I, Zoli W, Gianni L, Milandri C, Zumaglini F, et al. Phase II study of gemcitabine, doxorubicin and paclitaxel (GAT) as first-line chemotherapy for metastatic breast cancer: a translational research experience. BMC Cancer. 2006; 21(6): 76-83. PMid:16551351 http://dx.doi.org/10.1186/1471-2407-6-76

[21] Ibrahim T, Fabbri M, Frassineti GL, Zoli W, Monti M, Ricotti L, et al. Doxorubicin, paclitaxel and gemcitabine: a Phase I study of a new sequential treatment in stage III B - IV breast cancer. J Chemother. 2003; 15(5): 488-494. PMid:14598942 
[22] Sánchez-Rovira P, Jaén A, González E, Porras I, Dueñas MR, Medina B, et al. Phase II trial of gemcitabine/doxorubicin/paclitaxel administered every other week in patients with metastatic breast cancer.Clin Breast Cancer. 2000; 1(3): 226-232. PMid:11899647 http://dx.doi.org/10.3816/CBC.2000.n.019

[23] Sánchez-Rovira P, Jaén A, González E, Porras I, Dueñas R, Medina B, et al. Biweekly gemcitabine, doxorubicin, and paclitaxel as first-line treatment in metastatic breast cancer. Final results from a phase II trial. Oncology (Williston Park). 2001; 15(2 Suppl 3): 44-47.

[24] Estévez LG, Sánchez-Rovira P, Dórmine M, Leon A, Calvo I, Jaén A, et al. Biweekly docetaxel and gemcitabine as neoadjuvant chemotherapy followed by adjuvant doxorubicin and cyclophosphamide therapy in stage II and III breast cancer patients: results of a phase II study. Clin Transl Oncol. 2007; 9(5): 317-22. http://dx.doi.org/10.1007/s12094-007-0059-7

[25] Schmid P, Krocker J, Schulz CO, Michniewicz K, Dieing A, Eggermann H, et al. Primary chemotherapy with gemcitabine, liposomal doxorubicin and docetaxel in patients with locally advanced breast cancer: results of a phase I trial. Antcancer Drugs. 2005; 16(1): 21-9. PMid:15613900 http://dx.doi.org/10.1097/00001813-200501000-00003

[26] Farmer P, Bonnefoi H, Anderle P, Cameron D, Wirapati P, Becette V, et all. A stroma-related gene signature predicts resistance to neoadjuvant chemotherapy in breast cancer. Nat Med. 2009; 15 (1): 68-74. PMid:19122658 http://dx.doi.org/10.1038/nm.1908

[27] Akashi-Tanaka S, Shimizu C, Ando M, Shibata T, Katsumata N, Kouno T, Terada K, Shien T, Yoshida M, Hojo T, Kinoshita T, Fujiwara Y, Yoshimura K. 21-Gene expression profile assay on core needle biopsies predicts responses to neoadjuvant endocrine therapy in breast cancer patients. Breast. 2009; 18 (3): 171-4. PMid:19410462 http://dx.doi.org/10.1016/j.breast.2009.03.005

[28] Korde LA, Lusa L, McShane L, Lebowitz PF, Lukes L, Camphausen K, et al. Gene expression pathway analysis to predict response to neoadjuvant docetaxel and capecitabine for breast cancer. Breast Cancer Res Treat. 2010; 119 (3): 685-99. PMid:20012355 http://dx.doi.org/10.1007/s10549-009-0651-3

[29] Marmé F, Werft W, Benner A, Burwinkel B, Sinn P, Sohn C, et al. FGFR4 Arg388 genotype is associated with pathological complete response to neoadjuvant chemotherapy for primary breast cancer. Ann Oncol. 2010; 21(8): 1636-42. PMid:20147743 http://dx.doi.org/10.1093/annonc/mdq017

[30] Chang HR, Glaspy J, Allison MA, Kass FC, Elashoff R, Chung DU, et al. Differential response of triple-negative breast cancer to a docetaxel and carboplatin-based neoadjuvant treatment. Cancer. 2010; 116(18): 4227-37. PMid:20549829

http://dx.doi.org/10.1002/cncr.25309 